\title{
Prevalence and antibiotic resistance of bacterial pathogens isolated from childhood diarrhea in Beijing, China (2010-2014)
}

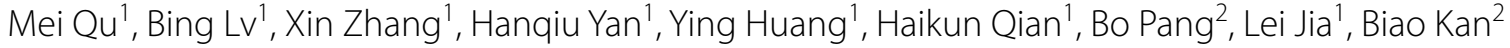 \\ and Quanyi Wang ${ }^{1 *}$
}

\begin{abstract}
Background: Diarrhea is one of the main causes of morbidity and mortality among children less than 5 years of age worldwide, and its causes vary by region. This study aimed to determine the etiologic spectrum, prevalent characteristics and antimicrobial resistance patterns of common enteropathogenic bacteria from diarrheagenic children in Beijing, the capital of China.

Methods: Stool samples were collected from 2524 outpatients who were aged $0-5$ years in Beijing, China during 2010-2014. Microbiological methods, real-time PCR and antimicrobial susceptibility test were used to identify the bacterial causes and antimicrobial resistance patterns in the isolates.

Results: Of the 2524 patients screened, we identified the causes of 269 cases (10.7\%) as follows: diarrheagenic Escherichia coli (4.6\%), Salmonella (4.3\%), Shigella (1.4\%) and Vibrio parahaemolyticus (0.4\%). Atypical EPEC, Salmonella enteritidis, Shigella sonnei and serotype O3:K6 were the most common serogroups or serotypes of the four etiological bacteria. The prevalence of pathogens was correlated with age, season and clinical symptoms. The highest proportion of all causative bacteria was found in children aged 3-5 years and in summer. The clinical symptoms associated with specific bacterial infection, such as fever; abdominal pain; vomiting; and watery, mucus, and bloody stool, were observed frequently in diarrheal patients. Salmonella showed moderate rates of resistance (40-60 \%) to ampicillin, nalidixic acid, streptomycin and sulfisoxazole. Resistance to at least three antimicrobials was found in $50 \%$ of isolates. Of the top three serotypes in Salmonella, high-level antimicrobial resistance to single and multiple antibiotics was more common among Salmonella typhimurium and Salmonella 1, 4, [5], 12:i:- than among S. enteritidis. More than $90 \%$ of Shigella isolates showed more alarming resistance to most antibiotics, with a widened spectrum compared to Salmonella.
\end{abstract}

Conclusion: Constant antibiotic surveillance is warranted because the bacteria were highly resistant to various antimicrobials. Our study contributes to the strengthening of the existing surveillance system and provides aid for effective prevention and control strategies for childhood diarrhea.

Keywords: Diarrhea surveillance, Diarrheagenic bacteria, Antimicrobial resistance, Children

\footnotetext{
*Correspondence: bjcdcxm@126.com

1 Department of Infectious and Endemic Diseases Control, Beijing Key Laboratory of Diagnostic and Traceability Technologies for Food Poisoning, Beijing Center for Disease Prevention and Control, No. 16 He Ping Li Middle Street, Beijing 100013, People's Republic of China Full list of author information is available at the end of the article
} 


\section{Background}

Diarrheal disease continues to be one of the foremost public health issues worldwide, with more than 1.5 million deaths each year, mostly in children under 5 years of age in industrializing countries. The average diarrheal disease incidence is an average of 2-3 episodes per child per year [1, 2]. In China, approximately 40,000 children suffer from diarrhea annually, especially during the first 2 years of life, and China remains one of the highest incidence countries [3]. Although diarrhea-associated mortality has roughly halved in the past 20 years, there is no indication that disease morbidity has decreased [4]. Moreover, there has been an alarming increase in the rate of resistance to commonly used antimicrobials. Therefore, acute diarrhea represents an important childhood ailment requiring treatment and prevention in China.

Recently, several specific diarrhea surveillance projects were conducted to explore the prevalence and etiology of bacterial infectious diseases in different regions in China [5-7]. Starting in April 2010, we established a real-time web-based diarrheal disease surveillance system based on sentinel hospitals for an unselected population of outpatients, which focused on common enteropathogenic bacteria accompanying clinical features, epidemiological information and laboratory confirmation in Beijing, China [8]. Through 5-year surveillance efforts and data accumulation, we aimed to identify the prevalence of the etiological spectrum, temporal distribution and antibiotic resistance patterns of bacterial pathogens associated with childhood diarrhea.

\section{Results and discussion}

\section{Demography of enrolled subjects}

From April 2010 to December 2014, 2524 stool specimens from outpatient children aged 0-5 years with acute diarrhea were collected and tested for bacterial pathogens. The outpatients comprised 1616 males and 908 females (male:female ratio $=1.8: 1$ and mean age $1.2 \pm 1.1$ years). Male children had a higher diarrheal incidence than female children, which was similar to the findings of other studies, despite the unknown explanation [9-11]. The age distribution showed that more than $90 \%$ of children suffering from diarrhea were less than 2 years old ( $\mathrm{n}=2341,92.7 \%$ ), and prevalence progressively decreased as age increased, in agreement with previous studies $[11,12]$. This difference in prevalence may be due to the gradual reduction in protective antibodies from the mother before the children have developed mature nervous and immune response against various infections [13]. Childhood acute diarrhea was more frequent in the summer than in other seasons. Of the 2524 enrolled subjects with an average frequency of diarrhea of $4.9 \pm 2.4,68.3 \%$ presented with mucus stool,
$30.0 \%$ with watery stool and $2.5 \%$ with bloody stool. The other clinical symptoms were not obvious, such as fever, accounting for $7.2 \%$ of the total, vomiting $(6.5 \%)$ and abdominal pain (4.4\%). However, $20.1 \%$ of the diarrheal children had a history of antibiotic use prior to admission (Table 1).

\section{Distribution of pathogenic bacteria by species and serotype}

At least one enteric pathogenic bacteria was isolated from 269 (10.7\%) of the 2524 stool specimens, with a total of 274 isolates. The prevalence of different bacteria is shown in Table 2. Diarrheagenic Escherichia coli (DEC) was the most common pathogen, isolated in 118 specimens (43.1 \%, 118/274), followed by Salmonella in 109 (39.8 \%), Shigella in 37 (13.5\%) and Vibrio parahaemolyticus in 10 (3.6\%). Among samples containing pathogenic bacteria ( $n=269$ ), single infections were observed in 264 (99.1\%) cases, and the remaining five cases of mixed infections had two pathogens, including DEC and Salmonella $(\mathrm{n}=3)$, DEC and Shigella $(\mathrm{n}=1)$, enteropathogenic E. coli (EPEC) and enteroaggregative E. coli (EAEC) $(\mathrm{n}=1)$.

The prevalence pattern of serogroup and serotype by region is diverse in different studies. DEC is an important etiologic agent of diarrhea in developing countries [14]. In this study, 118 DEC isolates were detected from nine virulence genes. The most prevalent category was EPEC, followed by EAEC, enterotoxigenic E. coli (ETEC), enteroinvasive E. coli (EIEC), and Shiga toxin-producing $E$. coli (STEC). Among the 67 EPEC strains, 58 strains carrying the eae gene only were grouped as atypical EPEC, and the other nine strains harboring the $b f p \mathrm{~A}$ and eae genes were typical EPEC. The atypical EPEC were more prevalent than typical EPEC (49.2 vs. $7.6 \%$ ), which is an emerging trend in developing and developed countries $[15,16]$. Although the etiologic role of this sub-pathotype of EPEC in diarrhea has not been definitively established [17], this finding underscores the emergence of atypical EPEC worldwide. EAEC (23.7\%) was the second most abundant $E$. coli, although it was the most prevalent in previous studies [7, 12, 18, 19]. This observed rate is in sharp contrast with the reported low and high detection rates of 17.4 and $31.8 \%$ in two previous studies from China $[6,7]$. In the 17 ETEC strains, the est and elt genes were detected in 9 and 6 strains, respectively, and both est and elt positive were found in two strains. Five EIEC strains produced ipa $\mathrm{H}$ gene, and the only STEC isolate positive for stx 1 and eae was O26:K60. The low prevalence of STEC and EIEC strains in this study is in agreement with the previous studies in China $[6,7]$ but differs from those in Iran and Tunisia, with high isolation rates $[12,20]$. As the four most prevalent serovars of 
Table 1 Demographic and illness characteristics of bacterial pathogens associated with childhood diarrhea in Beijing

\begin{tabular}{|c|c|c|c|c|c|c|}
\hline Characteristic & $\begin{array}{l}\text { All enrolled } \\
\text { subjects } \\
(n=2524)\end{array}$ & $\begin{array}{l}\text { Diarrheagenic } \\
\text { E. coli }(\mathrm{n}=117)^{\mathrm{a}}\end{array}$ & $\begin{array}{l}\text { Salmonella spp. } \\
(n=109)\end{array}$ & $\begin{array}{l}\text { Shigella spp. } \\
(\mathrm{n}=37)\end{array}$ & $\begin{array}{l}\text { V. parahaemolyticus } \\
(\mathrm{n}=10)\end{array}$ & $\begin{array}{l}\text { Total of all } \\
\text { pathogens } \\
(n=269)\end{array}$ \\
\hline \multicolumn{7}{|l|}{ Age (years), n (\%) } \\
\hline$<1$ & $1497(59.3)$ & $53(3.5)$ & $44(2.9)$ & $5(0.3)$ & $6(0.4)$ & $107(7.1)$ \\
\hline $1-2$ & $844(33.4)$ & $58(6.9)$ & $52(6.2)$ & $16(1.9)$ & $4(0.5)$ & 127 15.0) \\
\hline $3-4$ & $131(5.2)$ & $5(3.8)$ & $11(8.4)$ & $9(6.9)$ & $0(0.0)$ & $25(19.1)$ \\
\hline$=5$ & $52(2.1)$ & $1(1.9)$ & $2(3.8)$ & $7(13.5)$ & $0(0.0)$ & $10(19.2)$ \\
\hline Mean age $\pm S D$ & $1.2(1.1)$ & $1.3(1.0)$ & $1.5(1.1)$ & $2.9(1.8)$ & $1.1(0.7)$ & $1.6(1.3)$ \\
\hline$P$ value & - & 0.002 & $<0.001$ & $<0.001$ & 0.836 & $<0.001$ \\
\hline \multicolumn{7}{|l|}{ Sex, n (\%) } \\
\hline Male & $1616(64.0)$ & $70(4.3)$ & $71(4.4)$ & $26(1.6)$ & $3(0.2)$ & $170(10.5)$ \\
\hline Female & $908(36.0)$ & $47(5.2)$ & $38(4.2)$ & $11(1.2)$ & $7(0.8)$ & $99(10.9)$ \\
\hline$P$ value & - & 0.333 & 0.517 & 0.302 & 0.025 & 0.765 \\
\hline \multicolumn{7}{|l|}{ Seasons, n (\%) } \\
\hline Spring (Mar-May) & $584(23.1)$ & $22(3.8)$ & $28(4.8)$ & $0(0.0)$ & $1(0.1)$ & $50(8.6)$ \\
\hline Summer (Jun-Aug) & 1029 (40.8) & $62(6.0)$ & $50(4.9)$ & $31(3.0)$ & $6(0.6)$ & $146(14.2)$ \\
\hline Autumn (Sep-Nov) & $615(24.4)$ & $27(4.4)$ & $25(4.1)$ & $6(0.9)$ & $3(0.5)$ & $61(9.9)$ \\
\hline Winter (Dec-Feb) & $296(11.7)$ & $6(5.1)$ & $6(5.1)$ & $0(0.0)$ & $0(0.0)$ & $12(2.0)$ \\
\hline$P$ value & - & 0.017 & 0.229 & $<0.001$ & 0.397 & $<0.001$ \\
\hline \multicolumn{7}{|l|}{ Symptom, n (\%) } \\
\hline Fever $\left(>38^{\circ} \mathrm{C}\right)$ & $181(7.2)$ & $3(2.6)^{b}$ & $21(19.3)^{b}$ & $14(37.8)^{b}$ & $0(0.0)$ & $38(14.1)^{b}$ \\
\hline Abdominal pain & $112(4.4)$ & $4(3.4)$ & $8(7.3)$ & $7(18.9)^{b}$ & $0(0.0)$ & $19(7.1)^{b}$ \\
\hline Vomiting & $165(6.5)$ & $6(5.1)$ & $5(4.6)$ & $9(24.3)^{b}$ & $0(0.0)$ & $20(7.4)$ \\
\hline Dehydration & $11(0.4)$ & $0(0.0)$ & $0(0.0)$ & $0(0.0)$ & $0(0.0)$ & $0(0.0)$ \\
\hline Watery diarrhea & $758(30.0)$ & $38(32.5)$ & $20(18.3)^{b}$ & $8(21.6)$ & $1(10.0)$ & $66(24.5)^{b}$ \\
\hline Mucus diarrhea & $1724(68.3)$ & $76(65.0)$ & $87(79.8)^{b}$ & $26(70.3)$ & $8(80.0)$ & $193(71.7)$ \\
\hline Bloody diarrhea & $63(2.5)$ & $2(1.7)$ & $7(6.4)^{b}$ & $3(8.1)^{b}$ & $1(10.0)$ & $13(4.8)^{b}$ \\
\hline $\begin{array}{l}\text { Meandiarrhea } \\
\quad \text { frequency } \pm \text { SD }\end{array}$ & $4.9(2.4)$ & $4.3(2.3)$ & $5.7(2.6)$ & $6.9(3.6)$ & $4.1(1.6)$ & $5.2(2.8)$ \\
\hline $\begin{array}{l}\text { Antibiotic consump- } \\
\text { tion }\end{array}$ & $507(20.1)$ & 25 (21.4) & $28(25.7)$ & $23(62.2)$ & $5(50.0)$ & 79 (29.4) \\
\hline
\end{tabular}

a One specimen was identified by mixed infection of EPEC and EAEC, therefore $\mathrm{n}=117$; SD standard deviation

b Chi square test was calculated by each symptomdue to different pathogen, all significant $P$ values below 0.05 was noted

Salmonella isolates, Salmonella enteritidis, Salmonella typhimurium, Salmonella 1, 4, [5], 12:i:- and Salmonella agona represented $32.1,13.8,11.9$ and $9.2 \%$, respectively. Other isolates belonged to 29 different serotypes, anyone of which was present in less than $5 \%$. Salmonella 1, 4, [5], 12:i:-, a monophasic variant of S. typhimurium, has increased considerably since the mid-1990s and currently represents one of the most common serotypes causing infection in many countries and Guangdong Province in China $[21,22]$. As the third most prevalent serotype, Salmonella 1, 4, [5], 12:i:- highlighted the importance associated with childhood diarrheal disease in this study. Of the 37 Shigella isolates, Shigella sonnei was the most prevalent species, accounting for $86.5 \%$. Four Shigella flexneri isolates were represented by serotypes $2 \mathrm{a}$ and 4c, and only one Shigella dysenteriae strain was detected. The clear predominance of $S$. sonnei differs from that found in the studies of other provinces in China and many developing countries [6, 7, 12, 23]; however, several Asian countries have recently experienced a transition from $S$. flexneri to $S$. sonnei, probably due to improvement of overall nutritional status, sanitation and socioeconomic status [24-26]. The dominant serotype of $V$. parahaemolyticus was O3:K6, accounting for $80 \%$. Two types of K untypeable (KUT), namely, O1:KUT and O3:KUT, accounted for $10 \%$, respectively.

\section{Prevalence of pathogenic bacteria associated with era, season, age and clinical symptoms}

Over a period of five consecutive years, the overall isolation rate of enteric bacteria showed a gradual decrease from $15.1 \%$ in 2010 to $10.7 \%$ in 2014 , with occasional 
Table 2 Distribution of different enteropathogenic bacteria $(n=274)$ isolated from diarrheal patients

\begin{tabular}{|c|c|}
\hline Any simple pathogen & No. of isolates (\%) \\
\hline Diarrheagenic E.coli ( $n=118,5$ serogroups) & $118(43.1)$ \\
\hline \multicolumn{2}{|l|}{ EPEC } \\
\hline Atypical (eae+ , bfpA-) & $58(49.2)$ \\
\hline Typical (eae+, bfpA +) & $9(7.6)$ \\
\hline \multicolumn{2}{|l|}{ EAEC } \\
\hline $\operatorname{aggR}+$ & $28(23.7)$ \\
\hline \multicolumn{2}{|l|}{ ETEC } \\
\hline est+ & $9(7.6)$ \\
\hline elt+ & $6(5.1)$ \\
\hline Both+ & $2(1.7)$ \\
\hline EIEC (ipaH +) & $5(4.2)$ \\
\hline $\operatorname{STEC}(\text { eae }+, s t \times 1+)^{\mathrm{a}}$ & $1(0.8)$ \\
\hline Salmonella spp. $(\mathrm{n}=109,33$ serotypes) & $109(39.8)$ \\
\hline S. enteritidis & $35(32.1)$ \\
\hline S. typhimurium & $15(13.8)$ \\
\hline Salmonella 1, 4, [5], 12:i:- & $13(11.9)$ \\
\hline S. agona & $10(9.2)$ \\
\hline S. paratyphiC & $4(3.7)$ \\
\hline S. infantis & $3(2.8)$ \\
\hline S. braenderup & $2(1.8)$ \\
\hline S.tennessee & $2(1.8)$ \\
\hline Other serotypes ${ }^{b}$ & $25(22.5)$ \\
\hline Shigella spp. ( $n=37,4$ serotypes) & $37(13.5)$ \\
\hline S. sonnei & $32(86.5)$ \\
\hline S. flexneri $2 a$ & $2(5.4)$ \\
\hline S. flexneri $4 \mathrm{c}$ & $2(5.4)$ \\
\hline S. dysenteriae 2 & $1(2.7)$ \\
\hline V. parahaemolyticus ( $n=10,3$ serotypes) & $10(3.6)$ \\
\hline V. parahaemolyticus O3:K6 & $8(80)$ \\
\hline V. parahaemolyticus O3:KUT & $1(10)$ \\
\hline V. parahaemolyticus O1:KUT & $1(10)$ \\
\hline Total & $274(100)$ \\
\hline \multicolumn{2}{|l|}{ Mixed infections $(n=5)$} \\
\hline EPEC/Salmonella (S. enteritidis) & 1 \\
\hline EPEC/Salmonella (S. infantis) & 1 \\
\hline EAEC/Salmonella (S. typhimurium) & 1 \\
\hline EPEC/Shigella (S. sonnei) & 1 \\
\hline EPEC/EAEC & 1 \\
\hline
\end{tabular}

a The serotype of STEC is O26:K60

${ }^{b}$ The sum of the other serotypes excluding the top 8 serotypeslisted above

interannual variation (Fig. 1). This isolation rate was much lower than the reported range of 28.0-55.1\% in other works $[12,27]$, taking into account the variation pertaining to geographical area, the types of enteric pathogens, diagnostic methods and social and educational conditions. In fact, recent studies have also shown lower incidence of infections in economically developed regions, such as Shanghai, in China $[7,28]$ because the progress of sanitary conditions has reduced the risk factors of diarrhea. In this study, different pathogens showed various change patterns over time. DEC was identified (with an isolation rate of $4.6 \%$ ) as the most prevalent pathogen, with an increased trend during the past 5 years. Salmonella, with an isolation rate of $4.3 \%$, has remained fairly constant in the past decade in China $[5,7,21,29,30]$ but is much higher than in Bangladesh $(0.78 \%)$ [31] and lower than in Brazil (38.4 \%) [9]. The present study also showed a significant decrease in diarrhea caused by Shigella (1.4\%) and V. parahaemolyticus $(0.4 \%)$. Although these results were consistent with multicenter data throughout China [6,7], due to the limited data covering only a few years, it could not be established whether this trend will be maintained or vary in subsequent years. Further studies in the same area are necessary to definitively confirm these trends and to verify whether they truly correspond to an epidemiologic change or are just a response to exceptional situations.

The etiologic bacteria were isolated throughout the year, with a seasonal peak in summer (June-August) (Fig. 1; Table 1), which was also observed in other studies and is strongly associated with environmental factors [32], such as ambient temperature, precipitation and humidity. Beijing, with a high population density, is located in Northeastern China in the northern warm zone. In summer, the hot and humid climate facilitates microbial breeding, and food is more vulnerable to bacterial contamination, which may influence the survival and transmission of pathogens. This study showed that Shigella-caused diarrhea had a distinct peak in August. $V$. parahaemolyticus prevalence presented no remarkable seasonal trend because of the limited number of isolates. Salmonella and DEC were detected throughout the year with seasonal fluctuation.

The prevalence of pathogen categories was correlated with outpatient age (Table 1). The proportion of all causative bacteria was highest in children aged 3-5 years $(19.1 \%, P<0.001)$. Shigella infection was the highest in the age group of 5 years $(13.5 \%, P<0.001)$. Salmonella-caused diarrhea was most common at the age of $3-4$ years $(8.4 \%, P<0.001)$, whereas DEC infection in the group of 3-4 years (3.8\%) was secondary to the group of $1-2$ years $(6.9 \%)(P=0.002) . V$. parahaemolyticus showed no variation with age. Therefore, continuous surveillance targeting high-risk groups is needed to monitor the variation of etiology and epidemiological features.

The prevalence of clinical symptoms was also correlated with the distribution of pathogen categories (Table 1). Fever was the most common in all bacterial infections, except $V$. parahaemolyticus $(P<0.001)$. Abdominal pain and vomiting were the highest in Shigella infection (18.9 


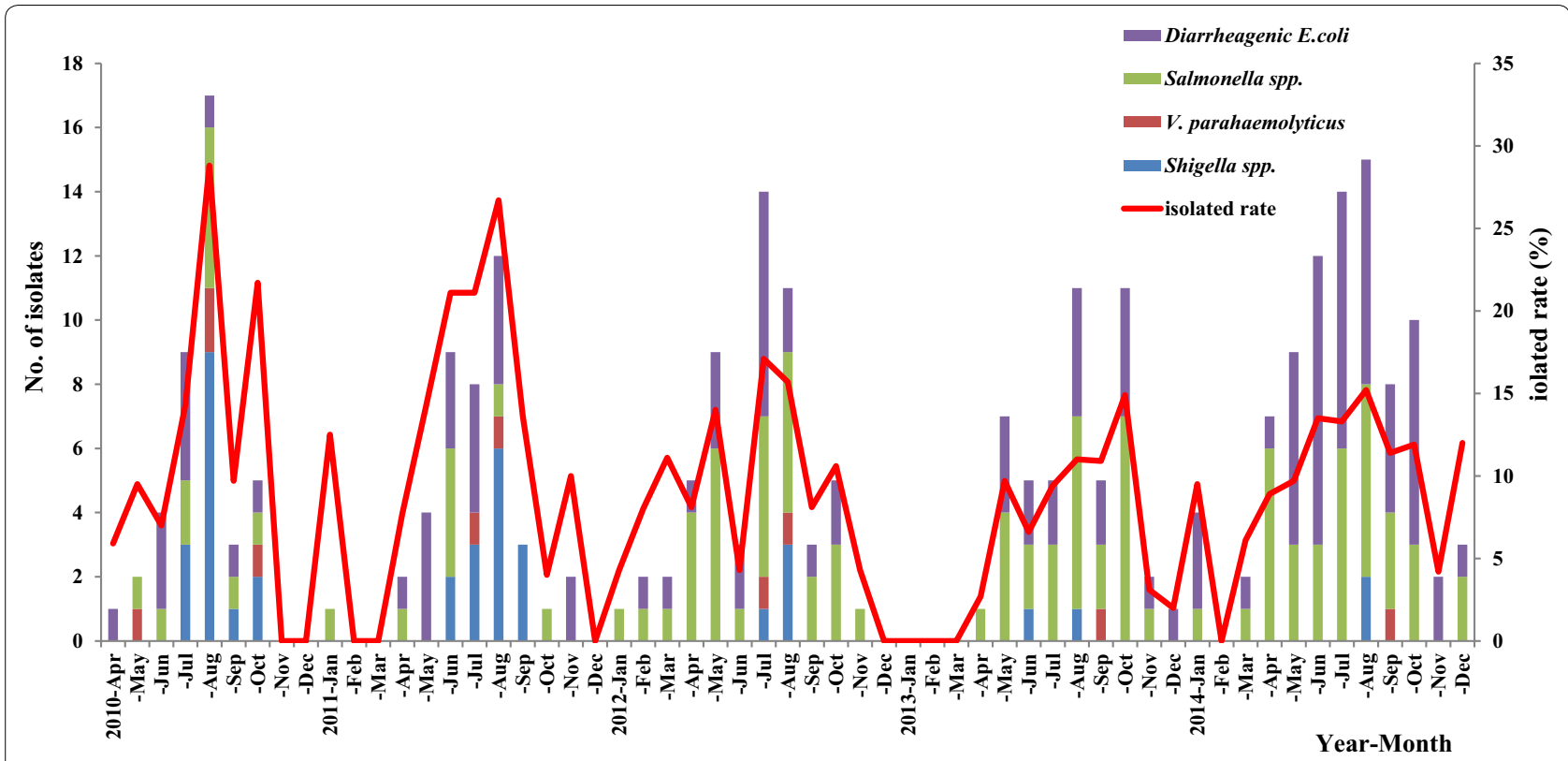

Fig. 1 Isolated rate of enteropathogens per month in Beijing during 2010-2014

and $24.3 \%$, respectively, $P<0.001)$. Salmonella infection caused mucus stool, watery stool and bloody stool in $79.8,18.3$ and $6.4 \%$ of cases, respectively (all $P<0.05$ ), whereas Shigella infection was significantly associated with only bloody stool $(8.1 \%, P=0.024)$.

\section{Antimicrobial resistance of Salmonella and Shigella}

Antimicrobial drug testing was performed on 109 Salmonella isolates and 37 Shigella isolates (Table 3). For the Salmonella isolates, resistance to nalidixic acid (NAL) was most common (56.0\%), followed by resistance to sulfisoxazole (SUL) (55.0\%), ampicillin (AMP) (46.8\%), streptomycin (STR) (44.0\%), tetracycline (TET) (29.4\%) and chloramphenicol (CHL) (16.5\%). The resistance profiles differed among different serotypes. S. typhimurium and Salmonella 1, 4, [5], 12:i:- isolates showed significantly higher resistance to most antibiotics than $S$. enteritidis isolates, similarly to previous studies [6, 21, 33]. Overall, the resistance of other serotypes was relatively lower than that of the top three dominant serotypes. Approximately $50 \%$ of Salmonella isolates were resistant to at least three antimicrobials, $41.3 \%$ were resistant to four, $22.9 \%$ were resistant to five and $12.8 \%$ were resistant to six. Many different patterns of resistance were observed with two predominant resistance patterns: AMP-STR-SUL-TET ( $\mathrm{n}=7,6.4 \%$ ) and AMP-STR-SULNAL $(n=6,5.5 \%)$.

The resistance of Shigella to nearly all antimicrobials was much more obvious than Salmonella, except CHL and ciprofloxacin (CIP). Of the 37 Shigella isolates, resistance to STR was most common (100\%), followed by resistance to NAL (97.3 \%), AMP (94.6\%), SUL (91.9\%) and gentamicin (GEN) (81.1\%). Moderate resistance to TET (45.9\%) and ceftriaxone (CRO) (29.7\%) was also observed; however, resistance to $\mathrm{CHL}$ and CIP was relatively low (16.2 and $2.7 \%$, respectively). All Shigella isolates were resistant to at least three antimicrobials, $94.6 \%$ of isolates were resistant to four or five antimicrobials and $56.8 \%$ were resistant to six. The two dominant antimicrobial resistant profiles were AMP-GEN-NALSTR-SUL ( $\mathrm{n}=12,32.4 \%$ ) and AMP-GEN-NAL-STRSUL-TET ( $\mathrm{n}=8,21.6 \%$ ). S. sonnei isolates were resistant to five $(96.9 \%)$ and six (56.3\%) antimicrobials, and of the four S. flexneri isolates, 100 and $75 \%$, respectively, were resistant to five and six antimicrobials. Although a similar pattern of resistance was reported in China and other Asian countries [6, 34, 35], the frequency of resistance reported here is higher, and the trend of multidrug resistance is more pronounced.

According to the WHO guidelines for the treatment of diarrhea, antimicrobials should not be used routinely, particularly for unknown causative agents. Antimicrobials are reliably helpful only for children with bloody diarrhea (probable shigellosis), suspected cholera with severe dehydration and serious non-intestinal infections, such as pneumonia [36]. Because the proportion of isolates resistant to AMP, CHL, SUL, STR, GEN and TET has increased substantially among Shigella isolates worldwide in the past decade, these drugs are no longer recommended as empirical therapy for shigellosis by 
Table 3 Antimicrobial resistance among Salmonella and Shigella isolates by serovars

\begin{tabular}{|c|c|c|c|c|c|c|c|c|c|}
\hline \multirow{2}{*}{$\begin{array}{l}\text { Antimicro- } \\
\text { bial }\end{array}$} & \multicolumn{6}{|c|}{ No. (\%) resistance of Salmonella species } & \multicolumn{3}{|c|}{ No. (\%) resistance of Shigella species } \\
\hline & $\begin{array}{l}\text { S. enteritidis } \\
(n=35)\end{array}$ & $\begin{array}{l}\text { S. typh- } \\
\text { imurium } \\
(\mathrm{n}=15)\end{array}$ & $\begin{array}{l}\text { 1, 4, [5], } \\
12::^{-} \\
(n=13)\end{array}$ & $\begin{array}{l}\text { S. agona } \\
(\mathrm{n}=10)\end{array}$ & $\begin{array}{l}\text { Overall } \\
(n=109)\end{array}$ & $\begin{array}{l}\text { S. sonnei } \\
(\mathrm{n}=32)\end{array}$ & $\begin{array}{l}\text { S. flexneri } \\
(n=4)\end{array}$ & $\begin{array}{l}\text { S. dysenteriae } \\
(n=1)\end{array}$ & $\begin{array}{l}\text { Overall } \\
(n=37)\end{array}$ \\
\hline AMP & $21(60.0)$ & $12(80.0)$ & $11(84.6)$ & $1(10.0)$ & $51(46.8)$ & $31(96.9)$ & $4(100.0)$ & $0(0.0)$ & $35(94.6)$ \\
\hline $\mathrm{CHL}$ & $3(8.6)$ & $8(53.3)$ & $4(30.8)$ & $1(10.0)$ & $18(16.5)$ & $2(6.3)$ & $4(100.0)$ & $0(0.0)$ & $6(16.2)$ \\
\hline CIP & $1(2.9)$ & $6(40.0)$ & $3(23.1)$ & $0(0.0)$ & $10(9.2)$ & $0(0.0)$ & $1(25.0)$ & $0(0.0)$ & $1(2.7)$ \\
\hline $\mathrm{CRO}$ & $7(20.0)$ & $0(0.0)$ & $2(15.4)$ & $0(0.0)$ & $10(9.2)$ & $10(31.3)$ & $1(25.0)$ & $0(0.0)$ & $11(29.7)$ \\
\hline GEN & $3(8.6)$ & $7(46.7)$ & $3(23.1)$ & $1(10.0)$ & $14(12.8)$ & $30(93.8)$ & $0(0.0)$ & $0(0.0)$ & $30(81.1)$ \\
\hline NAL & $34(97.1)$ & $9(60.0)$ & $5(38.5)$ & $1(10.0)$ & $61(56.0)$ & $32(100.0)$ & $4(100.0)$ & $0(0.0)$ & $36(97.3)$ \\
\hline STR & $15(42.9)$ & $10(66.7)$ & $12(92.3)$ & $2(20.0)$ & $48(44.0)$ & $32(100.0)$ & $4(100.0)$ & $1(100.0)$ & $37(100.0)$ \\
\hline SUL & $19(54.3)$ & $12(80.0)$ & $9(69.2)$ & $2(20.0)$ & $60(55.0)$ & $32(100.0)$ & $1(25.0)$ & $1(100.0)$ & $34(91.9)$ \\
\hline TET & $7(20.0)$ & $10(66.7)$ & $10(76.9)$ & $1(10.0)$ & $32(29.4)$ & $12(37.5)$ & $4(100.0)$ & $1(100.0)$ & $17(45.9)$ \\
\hline \multicolumn{10}{|c|}{ Multidrug-resistance (MDR) } \\
\hline MDR3 & $22(62.9)$ & $12(80.0)$ & $11(84.6)$ & $1(10.0)$ & $54(50.0)$ & $32(100)$ & $4(100.0)$ & $1(100)$ & $37(100)$ \\
\hline MDR4 & $17(48.6)$ & $12(80.0)$ & $9(69.2)$ & $1(10.0)$ & $45(41.3)$ & $31(96.9)$ & $4(100.0)$ & $0(0.0)$ & 35 (94.6) \\
\hline MDR5 & $7(20.0)$ & $10(66.7)$ & $5(38.5)$ & $1(10.0)$ & $25(22.9)$ & 31 (96.9) & $4(100.0)$ & $0(0.0)$ & 35 (94.6) \\
\hline MDR6 & $2(5.7)$ & $7(46.7)$ & $4(30.8)$ & $1(10.0)$ & $14(12.8)$ & $18(56.3)$ & $3(75.0)$ & $0(0.0)$ & $21(56.8)$ \\
\hline
\end{tabular}

For 109 Salmonella isolates, two dominant resistance patterns are AMP-STR-SUL-TET $(n=7,6.4 \%$ ) and AMP-STR-SUL-NAL ( $n=6,5.5 \%$ )

For 37 Shigella isolates, two dominant resistant patternsare AMP-GEN-NAL-STR-SUL $(n=12,32.4 \%)$ and AMP-GEN-NAL-STR-SUL-TET ( $\mathrm{n}=8$, $21.6 \%$ )

AMP ampicillin, CRO ceftriaxone, CIP ciprofloxacin, NAL nalidixic acid, TET tetracycline, GEN gentamicin, CHL chloramphenicol, SUL sulfisoxazole, STR streptomycin, MDR3 resistance to any three antibiotics, MDR4 resistance to any four antibiotics and so on

the WHO. Cephalosporins and fluoroquinolones are two popular acceptable options to treat severe gastrointestinal infections caused by pathogenic bacteria. As the third generation of the above two kinds of antibiotics, CRO and CIP are the drugs of choice for all patients with bloody diarrhea according to the WHO, irrespective age [36]. However, the 9.3 and $29.7 \%$ prevalence of resistance to CRO in Salmonella and Shigella isolates from diarrheal children was noteworthy in Beijing. Additionally, our study showed, respectively, 9.2 and $2.7 \%$ resistance rates to CIP in Salmonella and Shigella isolates, which is an alarming development that may also exist in other regions, such as Shanghai and Anhui in China [37, 38].

Antibiotic use outside hospitals without a medical prescription is very common, and most patients (65\%) with a diarrheal illness in China are treated with antibiotics without identification of the causative pathogen [39]. In this study, $20.1 \%$ of children had taken antibiotics prior to admission, whereas only $2.5 \%$ had bloody diarrhea. The widespread use of antimicrobial agents in the treatment of infections is responsible for the alarming rate of increase of multiple antimicrobial resistance and poses a great challenge. Serious constraints should be imposed on the antibiotics available for treatment of diarrhea among pediatricians. Even for therapy, antimicrobial treatment strategies must be designed to ensure safety and efficacy based on current resistance patterns.

\section{Conclusion}

The current surveillance system can identify only the common bacterial pathogens without understanding the patterns of viral and parasitic infection, which should be included to make the findings of the study more complete and valuable. To date, we can characterize only the resistance patterns for Salmonella and Shigella. As the active surveillance continues, we will further explore the etiologic spectrum and variation trends in antimicrobial resistance so that we can execute earlier and proper intervention to decrease the financial load on the patient and on health care.

\section{Methods}

\section{Study design and population}

The active surveillance program, the Enterobacterial Communicable Disease Surveillance (ECDS), was conducted from April 2010 to December 2014 in Beijing, the capital of China. Seventeen sentinel hospitals affiliated with six districts with different geographical and socioeconomic situation enrolled outpatients with acute diarrhea on two random days per week. A total of 2524 children under 5 years of age who were admitted with acute diarrhea diseases were included in this study. Clinical examination of each patient by a physician was followed by treatment and monitoring. The clinical and epidemiological information was recorded through the electronic gastrointestinal clinic surveillance 
and reporting system. Enrollment was subject to obtaining informed verbal consent from the parent or guardian who accompanied the child. All specimens were collected on the day of presentation by rectal swabs in Cary-Blair transport media and were immediately transported to the laboratory of Disease Prevention and Control (CDC) for processing within $24 \mathrm{~h}$.

\section{Detection of bacteria}

All specimens were processed by routine microbiologic and biochemical tests to identify different enteropathogenic bacteria. Each stool specimen was cultured by streaking on xylose-lysine deoxycholate (XLD) agar and Salmonella-Shigella agar (Becton-Dickinson Co., Sparks, MD, USA) for Shigella spp., and Salmonella spp., respectively, and incubating at $37^{\circ} \mathrm{C}$ for $16-24$ h. For S. typhi, swabs were enriched in Selenite brilliant-green broth (Becton-Dickinson Co., Sparks, MD, USA) at $37^{\circ} \mathrm{C}$ overnight, followed by sub-culturing on the media described above. For selective enrichment of Vibrio spp., swabs were inoculated on peptone water containing $3 \% \mathrm{NaCl}, \mathrm{pH} 8$, were incubated at $37^{\circ} \mathrm{C}$ overnight, inoculated on CHROMagar Vibrio media (CHROMagar Co., Paris, France), and incubated for 16-24 h. After culturing, at least five colonies morphologically resembling specific species were selected for further identification by biochemical testing according to standard methods. For other enteropathogenic bacteria, the systematic identification was confirmed with a VITEK 2 Compact instrument (bioMérieux, Marcyl'Etoile, France). Finally, serotyping was performed by slide agglutination test using commercially available antisera (Salmonella antisera from State Serum SSI Diagnostica, Denmark, Shigella and Vibrio antisera from Denka Seiken, Tokyo, Japan).

\section{Real-time PCR assay for diarrheagenic E. coli}

Pathotypes of DEC were identified by real-time PCR, including EAEC, EIEC, EPEC, ETEC and STEC. E. colilike and other gram-negative colonies growing on MacConkey agar were tested for the presence of virulence genes using seven sets of primers targeting aggR, stx 1 , st $x 2$, ip $a \mathrm{H}, b f p \mathrm{~A}$, eae, elt and est (Additional file 1). The real-time PCR assay was performed using the TaqMan ${ }^{\circledR}$ Universal PCR Master Mix Kit (Applied Biosystems, USA) on an Applied Biosystems 7500 Real-Time PCR System. The reaction mixture consisted of 2X PCR Master Mix, $200 \mathrm{nM}$ of forward and reverse primers, and $200 \mathrm{nM}$ of TaqMan probe. The amplification profile consisted of heat activation at $95^{\circ} \mathrm{C}$ for $10 \mathrm{~min} ; 40$ cycles of denaturation at $95{ }^{\circ} \mathrm{C}$ for $15 \mathrm{~s}$, annealing, extension, and fluorogenic signal detection at $60{ }^{\circ} \mathrm{C}$ for $1 \mathrm{~min}$. The assay was considered positive when the number of cycles to detection was 35 or less with the standard S curve.

\section{Antimicrobial susceptibility testing}

The antibiotic resistance of the bacterial isolates was tested using the Kirby-Bauer disk diffusion method following the guidelines of the Clinical and Laboratory Standards Institute (CLSI 2010). E. coli (ATCC 25922) was included in the test for quality control. The disk concentrations of 9 antimicrobial agents (Oxide, UK) were as follows: $10 \mu \mathrm{g}$ AMP, $30 \mu \mathrm{g}$ CRO, $5 \mu \mathrm{g}$ CIP, $30 \mu \mathrm{g}$ NAL, $30 \mu \mathrm{g}$ TET, $10 \mu \mathrm{g}$ GEN, $30 \mu \mathrm{g}$ CHL, $300 \mu \mathrm{g}$ SUL, and $10 \mu \mathrm{g}$ STR. Multidrug resistance was defined as resistance to at least three classes of antibiotics.

\section{Statistical analysis}

All data were entered in an Excel database (Additional file 2) (Microsoft Corporation, USA). Statistical analysis was performed with SPSS/11.5 software (SPSS Inc., USA). Comparison of proportions and statistical significance were calculated using a two-tailed Chi square test or Fisher's exact test with a $P<0.05$ considered significant.

\section{Additional files}

Additional file 1. Primers and probes used for real-time PCR for detection of diarrhoeagenic E. coli.

Additional file 2. Basic information and antimicrobial resistance of all strains isolated from diarrheal children.

\section{Abbrevations}

DEC: diarrheagenic Escherichia coli; EPEC: enteropathogenic Escherichia coli; EAEC: enteroaggregative Escherichia coli; ETEC: enterotoxigenic Escherichia coli; EIEC: enteroinvasive Escherichia coli; STEC: shiga toxin-producing Escherichia coli; KUT: Kuntypeable; NAL: nalidixic acid; SUL: sulfisoxazole; AMP: ampicillin; STR: streptomycin; TET: tetracycline; CHL: chloramphenicol; CIP: ciprofloxacin; GEN: gentamicin; CRO: ceftriaxone; MDR: multidrug-resistance; ECDS: enterobacterial communicable disease surveillance; CDC: disease prevention and control; XLD: xylose-lysine deoxycholate; CLSI: Clinical and Laboratory Standards Institute.

\section{Authors' contributions}

QYW designed the experiment. MQ, XZ, HQY, YH, HKQ, PB and $L J$ performed the experiment. MQ, BL and BK wrote the manuscript. All authors read and approved the final manuscript.

\section{Author details}

${ }^{1}$ Department of Infectious and Endemic Diseases Control, Beijing Key Laboratory of Diagnostic and Traceability Technologies for Food Poisoning, Beijing Center for Disease Prevention and Control, No. 16 He Ping Li Middle Street, Beijing 100013, People's Republic of China. ${ }^{2}$ State Key Laboratory for Infectious Disease Prevention and Control, National Institute for Communicable Disease Control and Prevention, Changping, Beijing 102206, People's Republic of China.

\section{Acknowledgements}

We thank the staff of the sentinel hospitals for the recruitment of the patients in the present study. We also thank the staff of six district CDCs (Changping CDC, Daxing CDC, Tongzhou CDC, Chaoyang CDC, Fengtai CDC, Xicheng CDC) for collecting epidemiological information and sample processing during the execution of this study.

\section{Availability of data and materials}

The database supporting the conclusions of this article is included within the article's Additional files. 


\section{Competing interests}

The authors declare that they have no competing interests.

\section{Compliance with ethical standards}

All procedures performed in this study involving human participants were in accordance with the ethical standards of the Beijing Center for Disease Prevention and Control's research committee.

\section{Funding}

This work was supported by a Grant from the National Key Program for Infec tious Disease of China (2016ZX10004215-005-001) and the Project of Beijing High-Level Technical Personnel Training in Health (2013-3-099).

Received: 26 February 2016 Accepted: 3 June 2016

Published online: 13 June 2016

\section{References}

1. Bryce J, Boschi-Pinto C, Shibuya K, Black RE, Group WHOCHER. WHO estimates of the causes of death in children. Lancet. 2005;365(9465):1147-52.

2. Walker $\mathrm{CL}$, Rudan I, Liu L, Nair H, Theodoratou E, Bhutta ZA, et al. Global burden of childhood pneumonia and diarrhoea. Lancet. 2013:381(9875):1405-16.

3. Liu HX, Zhang J. Analysis of reported infectious diarrhea (other than cholera, dysentery, typhoid and paratyphoid) in China in 2011. Zhonghua Yu Fang Yi Xue Za Zhi. 2013;47(4):328-32.

4. Liu L, Johnson HL, Cousens S, Perin J, Scott S, Lawn JE, et al. Global, regional, and national causes of child mortality: an updated systematic analysis for 2010 with time trends since 2000. Lancet. 2012:379(9832):2151-61.

5. Ran L, Wu S, Gao Y, Zhang X, Feng Z, Wang Z, et al. Laboratory-based surveillance of nontyphoidal Salmonella infections in China. Foodborne Pathog Dis. 2011;8(8):921-7.

6. Zhang H, Pan F, Zhao X, Wang G, Tu Y, Fu S, et al. Distribution and antimicrobial resistance of enteric pathogens in Chinese paediatric diarrhoea: a multicentre retrospective study, 2008-2013. Epidemiol Infect. 2015;143(12):2512-9.

7. Yu J, Jing H, Lai S, Xu W, Li M, Wu J, et al. Etiology of diarrhea among children under the age five in China: results from a 5-year surveillance. J Infect. 2015;71(1):19-27.

8. Qu M, Deng Y, Zhang X, Liu G, Huang Y, Lin C, et al. Etiology of acute diarrhea due to enteropathogenic bacteria in Beijing. China. J Infect. 2012;65(3):214-22.

9. Diniz-Santos DR, Santana JS, Barretto JR, Andrade MG, Silva LR. Epidemiological and microbiological aspects of acute bacterial diarrhea in children from Salvador, Bahia, Brazil. Braz J Infect Dis. 2005;9(1):77-83.

10. Moyo SJ, Gro N, Matee Ml, Kitundu J, Myrmel H, Mylvaganam H, et al. Age specific aetiological agents of diarrhoea in hospitalized children aged less than 5 year in Dar es Salaam, Tanzania. BMC Pediatr. 2011;11:19.

11. Rathaur VK, Pathania M, Jayara A, Yadav N. Clinical study of acute childhood diarrhoea caused by bacterial enteropathogens. J Clin Diagn Res. 2014:8:PC01-5

12. Jafari F, Garcia-Gil LJ, Salmanzadeh-Ahrabi S, Shokrzadeh L, Aslani MM, Pourhoseingholi MA, et al. Diagnosis and prevalence of enteropathogenic bacteria in children less than 5 years of age with acute diarrhea in Tehran children's hospitals. J Infect. 2009;58(1):21-7.

13. Nic Fhogartaigh C, Dance DAB. Bacterial gastroenteritis. Medicine. 2013:41(12):693-9.

14. Thapar N, Sanderson IR. Diarrhoea in children: an interface between developing and developed countries. Lancet. 2004;363(9409):641-53.

15. Nataro JP. Atypical enteropathogenic Escherichia coli: typical pathogens? Emerg Infect Dis. 2006;12(4):696.

16. Nguyen RN, Taylor LS, Tauschek M, Robins-Browne RM. Atypical enteropathogenic Escherichia coli infection and prolonged diarrhea in children. Emerg Infect Dis. 2006;12(4):597-603.
17. Nataro JP, Mai V, Johnson J, Blackwelder WC, Heimer R, Tirrell S, et al Diarrheagenic Escherichia coli infection in Baltimore, Maryland, and New Haven, Connecticut. Clin Infect Dis. 2006:43(4):402-7.

18. Nair GB, Ramamurthy T, Bhattacharya MK, Krishnan T, Ganguly S, Saha DR et al. Emerging trends in the etiology of enteric pathogens as evidenced from an active surveillance of hospitalized diarrhoeal patients in Kolkata, India. Gut Pathog. 2010;2(1):4

19. Saeed A, Abd H, Sandstrom G. Microbial aetiology of acute diarrhoea in children under 5 years of age in Khartoum, Sudan. J Med Microbiol. 2015;64(Pt 4):432-7.

20. Al-Gallas N, Bahri O, Bouratbeen A, Ben Haasen A, Ben Aissa R. Etiology of acute diarrhea in children and adults in Tunis, Tunisia, with emphasis on diarrheagenic Escherichia coli: prevalence, phenotyping, and molecular epidemiology. Am J Trop Med Hyg. 2007;77(3):571-82.

21. Ke B, Sun J, He D, Li X, Liang Z, Ke CW. Serovar distribution, antimicrobial resistance profiles, and PFGE typing of Salmonella enterica strains isolated from 2007 to 2012 in Guangdong, China. BMC Infect Dis. 2014;14:338.

22. Switt Al, Soyer Y, Warnick LD, Wiedmann M. Emergence, distribution, and molecular and phenotypic characteristics of Salmonella enterica serotype 4,5,12:i. Foodborne Pathog Dis. 2009:6(4):407-15.

23. Niyogi SK, Pazhani GP. Multiresistant Shigella species isolated from childhood diarrhea cases in Kolkata, India. Jpn J Infect Dis. 2003:56(1):33-4.

24. Bangtrakulnonth A, Vieira AR, Lo Fo Wong DM, Pornreongwong S, Pulsrikarn C, Sawanpanyalert P, et al. Shigella from humans in Thailand during 1993-2006: spatial-time trends in species and serotype distribution. Foodborne Pathog Dis. 2008;5(6):773-84.

25. Vinh H, Nhu NT, Nga TV, Duy PT, Campbell Jl, Hoang NV, et al. A changing picture of shigellosis in southern Vietnam: shifting species dominance, antimicrobial susceptibility and clinical presentation. BMC Infect Dis. 2009;9:204

26. von Seidlein L, Kim DR, Ali M, Lee H, Wang X, Thiem VD, et al. A multicentre study of Shigella diarrhoea in six Asian countries: disease burden, clinical manifestations, and microbiology. PLoS Med. 2006:3(9):e353.

27. Langendorf C, Le Hello S, Moumouni A, Gouali M, Mamaty AA, Grais $\mathrm{RF}$, et al. Enteric bacterial pathogens in children with diarrhea in Niger: diversity and antimicrobial resistance. PLoS ONE. 2015;10(3):e0120275.

28. Zhang Y, Zhao Y, Ding K, Wang X, Chen X, Liu Y, et al. Analysis of bacterial pathogens causing acute diarrhea on the basis of sentinel surveillance in Shanghai, China, 2006-2011. Jpn J Infect Dis. 2014;67(4):264-8.

29. Xia S, Hendriksen RS, Xie Z, Huang L, Zhang J, Guo W, et al. Molecular characterization and antimicrobial susceptibility of Salmonella isolates from infections in humans in Henan Province, China. J Clin Microbiol. 2009;47(2):401-9.

30. Koziel M, Kiely R, Blake L, O'Callaghan I, Corcoran GD, Lucey B, et al. Improved detection of bacterial pathogens in patients presenting with gastroenteritis by use of the EntericBio real-time gastro panel I assay. J Clin Microbiol. 2013;51(8):2679-85.

31. Haque R, Mondal D, Kirkpatrick BD, Akther S, Farr BM, Sack RB, et al. Epidemiologic and clinical characteristics of acute diarrhea with emphasis on Entamoeba histolytica infections in preschool children in an urban slum of Dhaka, Bangladesh. Am J Trop Med Hyg. 2003:69(4):398-405.

32. Naumova EN, Jagai JS, Matyas B, DeMaria A Jr, MacNeill IB, Griffiths JK. Seasonality in six enterically transmitted diseases and ambient temperature. Epidemiol Infect. 2007;135(2):281-92.

33. Zhu M, Cui S, Lin L, Xu B, Zhao J, Xia S, et al. Analysis of the aetiology of diarrhoea in outpatients in 2007, Henan province, China. Epidemiol Infect. 2013:141(3):540-8

34. Tiruneh M. Serodiversity and antimicrobial resistance pattern of Shigella isolates at Gondar University teaching hospital, Northwest Ethiopia. Jpn J Infect Dis. 2009;62(2):93-7.

35. Bhattacharya D, Sugunan AP, Bhattacharjee $H$, Thamizhmani $R$, Sayi DS, Thanasekaran K, et al. Antimicrobial resistance in Shigella-rapid increase and widening of spectrum in Andaman Islands, India. Indian J Med Res. 2012:135:365-70.

36. Bhan MK. The treatment of diarrhea. Geneva: World Health Organization. 2005. http://www.who.int/maternal_child_adolescent/ documents/9241593180/en/ 
37. Yang H, Chen G, Zhu Y, Liu Y, Cheng J, Hu L, et al. Surveillance of antimicrobial susceptibility patterns among Shigella species isolated in China during the 7-year period of 2005-2011. Ann Lab Med. 2013;33(2):111-5

38. Zhang J, Jin H, Hu J, Yuan Z, Shi W, Yang X, et al. Antimicrobial resistance of Shigella spp. from humans in Shanghai, China, 2004-2011. Diagn Microbiol Infect Dis. 2014;78(3):282-6.
39. Ke B, Ran L, Wu S, Deng X, Ke C, Feng Z, et al. Survey of physician diagnostic and treatment practices for patients with acute diarrhea in Guangdong province, China. Foodborne Pathog Dis. 2012;9(1):47-53.

\section{Submit your next manuscript to BioMed Central and we will help you at every step:}

- We accept pre-submission inquiries

- Our selector tool helps you to find the most relevant journal

- We provide round the clock customer support

- Convenient online submission

- Thorough peer review

- Inclusion in PubMed and all major indexing services

- Maximum visibility for your research

Submit your manuscript at

www.biomedcentral.com/submit 